\title{
La instrumentalización del despido ineficaz como garantía del derecho al trabajo. Estudio en Machala, Ecuador
}

Ab. María Cecilia Martínez Arias momartineza3000@gmail.com

Mg. Guido Peña Armijos gpenaarmijos@gmail.com

Universidad Técnica de Machala - UTMACH

\section{RESUMEN}

Machala - Ecuador

Como se conoce, el despido ineficaz respalda jurídicamente a los grupos más vulnerables como: mujeres embarazadas en estado de gestación o en período de lactancia y dirigentes sindicales. El empleado/a que considere ser víctima de despido ineficaz debe denunciarlo en un plazo máximo de 30 días. Uno de los objetivos claves de su implementación es garantizar que se cumpla el principio de la estabilidad laboral. A pesar de esta garantía, en el régimen actual se presentan ciertas vulnerabilidades no contempladas en las leyes que son destacadas en la presente investigación. Dichas vulnerabilidades han sido obtenidas por medio de un análisis descriptivo - documental y también en base de la experiencia de los autores.

Palabras claves: Despido ineficaz, vulnerabilidades, estabilidad laboral, principios jurídicos, derechos 


\title{
The instrumentalization of ineffective dismissal as a guarantee of the right to work. Study in Machala, Ecuador
}

\begin{abstract}
As is known, ineffective dismissal legally supports the most vulnerable groups such as: pregnant women in a state of pregnancy or breastfeeding and union leaders. The employee who considers being a victim of ineffective dismissal must report it within a maximum period of 30 days. One of the key objectives of its implementation is to ensure that the principle of job stability is met. Despite this guarantee, the current regime presents certain vulnerabilities not contemplated in the laws that are highlighted in this investigation. Said vulnerabilities have been obtained through a descriptive-documentary analysis and also based on the experience of the authors.
\end{abstract}

Keywords: Ineffective dismissal, vulnerabilities, job stability, legal principles, rights.

Artículo recibido: 05 de Mayo 2021 Aceptado para publicación: 20 de Junio 2021 Correspondencia: mcmartineza3000@gmail.com Conflictos de Interés: Ninguna que declarar 


\section{INTRODUCCIÓN}

Como se conoce, de acuerdo a la Constitución y a la ley, el despido ineficaz se aplica a las mujeres embarazadas y en periodo de lactancia, así como también se extiende a los dirigentes sindicales y personas discapacitadas. En muchas ocasiones ante este tipo de despido, el empleado opta por recibir una indemnización sin mediar el regreso a su trabajo e intentar conservar su empleo; convirtiéndose este comportamiento en ciertos casos en un modus vivendi. Casos como este dan a pensar a priori que en la ley existen en la ley vulnerabilidades, a pesar de que el espíritu de esta disposición es precautelar el empleo y el derecho al trabajo.

\section{MARCO TEÓRICO}

\subsection{Antecedentes históricos}

En ciertos casos se han dado abusos por parte de los empleadores en las relaciones laborales, así como por parte de los trabajadores. Para que estos abusos dejen de darse, se han considerado reformas al Código de Trabajo que junto con la Ley para la Justicia Laboral y el Trabajo en el Hogar ponen en la palestra jurídica la figura del despido ineficaz (Quevedo \& Tigua, 2017).

Las leyes que corresponden a despido ineficaz se consideraron en Ecuador a partir de abril de 2015, cuando en el Código de Trabajo se puso en vigencia la Ley Orgánica para la Justicia Laboral y Reconocimiento del Trabajo en el Hogar, que consideró disposiciones para la gestión del talento humano y que constituyeron un cambio de postura para los empleadores.

A pesar de que el despido ineficaz parece novedoso, este tiene como origen el "despido injustificado", el cual está normado en el artículo 7 del Protocolo de San Salvador, normativa internacional que está ratificada en nuestro país. El Protocolo mencionado que se declaró en la Convención Americana sobre Derechos Humanos en 1988, advierte que, en casos de despido injustificado, el trabajador tendrá derecho a una indemnización o a la readmisión en el empleo o a cualquiera otra prestación prevista por las leyes nacionales vigentes. (Quevedo \& Tigua, 2017).

\subsection{Antecedentes conceptuales y referenciales}

Las palabras claves que delinean la presente teoría de soporte los antecedentes conceptuales y referenciales se ilustran en la figura 1, la cual se muestra a continuación. 
Figura 1. Soporte teórico para el tratamiento del despido ineficaz

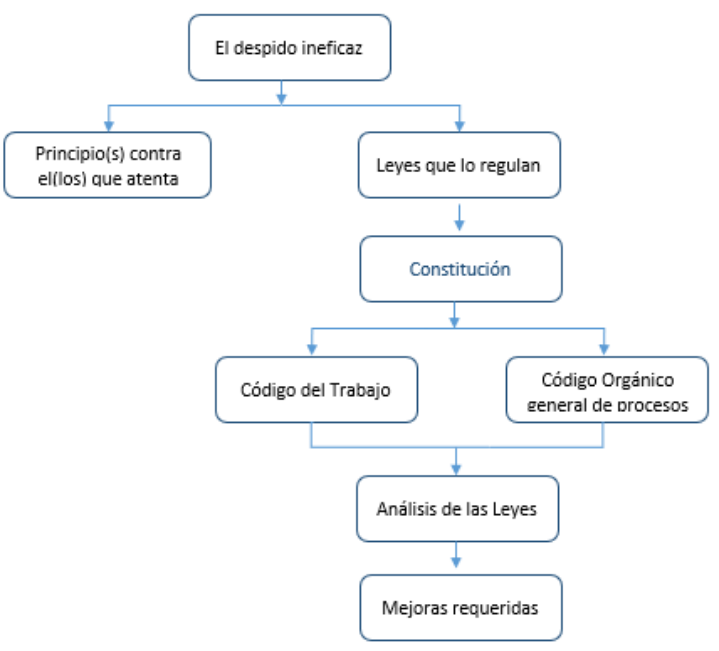

Elaborado por Martínez (2020)

\section{Despido ineficaz}

La decisión del empleador de concluir una relación laboral con una trabajadora que se encuentre embarazada o asociada a su condición de gestación o maternidad, las mismas reglas serán aplicables a los dirigentes sindicales; se considera despido intempestivo que se torna ineficaz cuando se ha dado de manera injustificada. Lo expuesto se ampara en la Constitución artículo 332 y en el Código de Trabajo artículo 195 numeral 1.

Mediante el artículo 332 de la Constitución (2018), el Estado garantiza el respeto a los derechos reproductivos de quienes laboran, lo cual contempla: la eliminación de riesgos laborales que vulneren la salud reproductiva de los empleados, el acceso a la estabilidad laboral sin limitaciones por embarazo o cantidad de hijos e hijas, derechos de maternidad y lactancia y derecho a licencia por paternidad. Continúa este artículo declarando que se prohíbe el despido de la mujer que labore, así como la discriminación vinculada con roles reproductivos.

En nuestro país a partir del 2008, la Asamblea Nacional instaura de acuerdo a la Constitución, la política del Buen Vivir, que ha sido actualizada en el 2017 bajo la guía del Consejo Nacional de Planificación. Esta política considerada por el Estado, busca en resumen que exista la igualdad e inclusión social de todos los ciudadanos.

El despido ineficaz es una garantía que tienen los trabajadores, la cual protege a los llamados grupos de atención prioritaria o los más vulnerables como: mujeres embarazadas o en estado de gestación y dirigentes sindicales. Con esta garantía, la ley les otorga, en el caso de que sean despedidos, estabilidad laboral, indemnización y el derecho 
a reintegrarse inmediatamente en sus funciones, pues debe primar el principio de la estabilidad laboral y el principio de inamovilidad que les ampara.

Una breve descripción de varios principios del Derecho relacionados con el tipo de despido en discusión se presenta a continuación.

\section{Principio de estabilidad laboral}

Es el derecho que se le concede a un empleado a mantenerse en el cargo que desempeña sin que sea despedido de manera injusta puesto que en caso de despido injustificado se requerirá la indemnización del caso o la oportunidad de se reintegre al trabajo.

\section{Principio de igualdad y no discriminación}

Toda persona está en goce de los derechos humanos, incluidos en derecho a la igualdad de trato ante la ley y el derecho a ser protegido contra la discriminación por ciertos motivos.

\section{Principio de derecho a la defensa}

Se trata del principio constitucional, mediante el cual toda persona, sin excepción, tiene derecho a ciertas garantías para asegurar un resultado justo - imparcial y equitativo dentro de un proceso, además de la oportunidad para ser oído y hacer valer sus derechos en un juzgado.

\section{Principio de inamovilidad}

De acuerdo al Derecho Procesal, el principio de inamovilidad es el derecho del cual gozan ciertos empleados y funcionarios, en especial jueces y magistrados, a no ser destituidos, suspendidos ni jubilados sin fundamento sino bajo el amparo de la ley (Enciclopedia jurídica, 2020).

\section{Derecho al trabajo}

Toda persona tiene derecho al trabajo. El derecho al trabajo es la base para gozar de una vida en dignidad. Comprende la oportunidad de ganarse la vida mediante un trabajo libremente escogido y/o aceptado, en condiciones equitativas y satisfactorias; esto incluye gozar de un salario justo. En derecho internacional se prohíbe el trabajo forzoso.

El trabajo debe realizarse en condiciones seguras, saludables y no degradantes. Todo empleador debe ofrecer a sus empleados un horario razonable, el descanso adecuado y vacaciones pagadas de manera periódica. 
Es importante destacar que los trabajadores tienen derecho a asociarse entre sí y negociar de manera colectiva para que se mejoren las condiciones laborales y el nivel de vida. Pueden formar a formar sindicatos o agrupaciones nacionales o internacionales.

Los empleados tienen derecho a la huelga si y sólo si se realice bajo el amparo de las leyes nacionales.

\section{Derecho a la seguridad social}

Este derecho está reconocido como un derecho humano y promueve el respaldo de la seguridad social para quienes estén imposibilitados de trabajar debido a enfermedad, algún tipo de discapacidad, maternidad, accidentes laborales, vejez u otra circunstancia. Los Estados deben realizar implementar este derecho a través de medidas para ofrecer protección, a través de dinero en cualquier forma, que permita a los individuos y las familias adquirir atención sanitaria al menos modesta y vivienda básica, así como las formas más básicas de educación.

\section{Derecho constitucional a la defensa}

Se trata de un principio constitucional y procesal, por el cual cualquier persona tiene ciertas garantías que aseguren un resultado justo y equitativo dentro de un proceso jurídico. Considerando este derecho, cualquier persona puede hacer respetar sus derechos en un proceso legal, con base en la igualdad de condiciones y facultades de las partes procesales.

El derecho a la defensa ha sido reconocido por tratados internacionales de derechos humanos, suscritos y ratificados por el Ecuador y luego incluidos en el ordenamiento jurídico a partir de la Constitución de la República.

\section{Leyes que regulan el despido ineficaz}

En las leyes ecuatorianas se encuentra tipificado el despido ineficaz, el cual pretende respaldar a las mujeres embarazadas o en estado de maternidad, así como a dirigentes sindicales.

El despido ineficaz atenta contra el derecho de estabilidad laboral que tenemos las personas. Esta premisa está respaldada por la Constitución del Ecuador (2018) en su artículo 66 numeral 2 que promueve "el derecho a una vida digna que asegure la salud, alimentación, ..., trabajo, empleo, ..., seguridad social y otros servicios sociales necesarios". 
En el artículo 195 numeral 1 del Código de Trabajo (2020) se menciona que "se considerará ineficaz el despido intempestivo de personas trabajadoras en estado de embarazo o asociado a su condición de gestación o maternidad, en razón del principio de inamovilidad que les ampara".

En este mismo numeral, se añade que "las mismas reglas sobre la ineficacia del despido serán aplicables a los dirigentes sindicales en cumplimiento de sus funciones por el plazo establecido en el artículo 187”.

En el artículo 195 numeral 2 del mismo Código, se enfatiza sobre la acción del despido ineficaz indicando:

Una vez producido el despido, la persona trabajadora afectada deberá deducir su acción ante la Jueza o el Juez del Trabajo de la jurisdicción correspondiente al lugar donde este se produjo, en el plazo máximo de treinta días.

Admitida a trámite la demanda, se mandará citar en el plazo de veinticuatro horas a la parte empleadora y, en la misma providencia, se podrán dictar las medidas cautelares que permitan el reintegro inmediato al trabajo del trabajador afectado o la trabajadora afectada, mientras dure el trámite.

A la demanda y a la contestación se acompañarán las pruebas de que se disponga y se solicitarán las que deban practicarse.

En la referida providencia se convocará a audiencia que se llevará a cabo en el plazo de cuarenta y ocho horas contadas desde la citación. Esta iniciará por la conciliación y, de existir acuerdo, se autorizará por sentencia. A falta de acuerdo se practicarán las pruebas solicitadas.

La Jueza o el Juez de Trabajo, dictarán sentencia en la misma audiencia.

Contra la sentencia que admita la ineficacia será admisible el recurso de apelación con efecto devolutivo.

\section{Observaciones}

Como indican Quevedo \& Tigua (2017) en el Código de Trabajo existen ciertos vacíos sobre el despido ineficaz, entre estos: (1) no se precisa cuál es el tiempo en que la mujer debe indicar su estado al empleador; (2) qué pasa si el empleador nunca conoció del estado de embarazo de la mujer y (3) si existe algún otro requisito para que un dirigente sindical que fue despedido injustamente se dirija debidamente ante la autoridad 
competente. Estos vacíos pueden ser considerados como una excepción y no procede el despido ineficaz.

El despido ineficaz no considera a las personas con discapacidad, Goyes (2019).

\subsection{Antecedentes contextuales}

En el país se han realizado algunos proyectos de titulación a nivel de grado y posgrado sobre despido ineficaz; sobresaliendo entre ellos los siguientes:

"Desafíos del despido ineficaz en Ecuador" de la autoría de Ariana Quevedo y Ana María Tigua (2017), dado en la Universidad Católica Santiago de Guayaquil (UCSG), en cuyo estudio se analiza de manera crítica al despido ineficaz, considerando: el Código del Trabajo; principios constitucionales (que protegen a los denominados grupos prioritarios) y vacíos que tiene la norma respecto a la notificación que debe existir por parte de la mujer en caso de que se encuentre embarazada.

"Análisis jurídico del despido ineficaz de las mujeres embarazadas en el período de prueba" cuyo autor es José Luis Arias Vásquez (2018). Este es una investigación que se realizó en la Universidad Regional Autónoma de Los Andes (UNIANDES) y en él se toma como base los derechos que tiene el empleado de acuerdo a la Constitución en especial el caso de las mujeres embarazadas. Mediante un estudio de campo se logró determinar que el análisis propuesto permitirá reconocer a las mujeres embarazadas sus derechos y se les garantice su estabilidad laboral.

"La estabilidad laboral, como principio fundamental del despido ineficaz" de la autoría de Pablo Andrés Basantes Portilla realizado en 2017 en la Universidad de los Hemisferios. En este trabajo, se describe a través de un análisis doctrinario y social al despido ineficaz, sus causas y consecuencias en la sociedad ecuatoriana que permita entender de manera práctica cómo se trata el proceso y efectos legales para el trabajador y el empleador.

"El derecho de la indemnización en la acción por despido ineficaz" cuyo autor es Juan Manuel Herrera Criollo; estudio que data del 2017 y que fue realizado en UNIANDES. En esta tesis se indica que debe tomarse en cuenta la decisión de la mujer embarazada de ser reintegrada a su puesto de trabajo o recibir su liquidación equivalente a un año de la última remuneración que recibía, además de la que le corresponde por despido intempestivo. 
“Análisis y crítica del despido ineficaz en el Ecuador”. Esta tesis tiene por autora a Stefany Kelly García Bermúdez y fue elaborada en el 2017 en la UCSG. En ella se hace hincapié de que el despido ineficaz ampara a las mujeres embarazadas y a los dirigentes sindicales, por ende, no todas las personas en relación de dependencia en este país cuentan con estabilidad laboral absoluta. Se mencionan vacíos legales y reformas que podrían realizarse para que finalicen abusos en ciertos casos por parte de los empleadores.

"El despido ineficaz en la legislación ecuatoriana y su seguridad jurídica" de Jeaneth Carolina Valenzuela Palacios, elaborada en el 2018 en UNIANDES. El estudio evidencia la falta de garantías constitucionales que se dan en los despidos ineficaces por parte de distintos empleadores.

\section{METODOLOGÍA}

\section{La investigación a realizar será de tipo descriptivo y documental.}

Como lo indica Bernal (2010), "la investigación documental consiste en un análisis de la información escrita sobre un determinado tema, con el propósito de establecer relaciones, diferencias, etapas, posturas o estado actual del conocimiento respecto al tema objeto de estudio". (p. 111).

En la presente investigación se utilizarán fuentes primarias y secundarias de información lo cual implica el análisis de una gran cantidad de documentos, archivos (digitales y/o físicos) correspondientes a diversos casos en los que se ha dado el despido ineficaz; por tanto, la utilización de la investigación documental se torna de carácter sine qua non.

Será parte de la investigación documental los estudios conocidos como estado del arte, los cuales muestran el estado actual del conocimiento para el objeto de estudio; en este caso el despido ineficaz.

Según Hernández, Fernández \& Baptista (2010) la investigación descriptiva "busca especificar propiedades, características y rasgos importantes de cualquier fenómeno que se analice".

En este trabajo, la investigación descriptiva permitirá en la presente investigación determinar características, efectos, límites, vacíos del despido ineficaz que se han dado en diversas situaciones y casos analizados.

En el enfoque de la investigación será mixto, puesto que se considerará un componente cualitativo y un componente cuantitativo. 
El enfoque mixto se da al considerar casos de la Inspectoría de Trabajo, en la Mediación, de tipo judicial, etc. que se relacionen con el despido ineficaz. En estos, se realizará:

- una estadística que mida la cantidad de demandas laborales por despido ineficaz, género de los empleados, demandas por despido ineficaz que llegan y que no llegan a juicio, etc. $y$

- se analizarán los motivos para que ese dictamen se haya dado.

\section{Como fuentes primarias de información se acudirá a:}

- la Inspectoría de Trabajo de la provincia de El Oro a solicitar evidencias de denuncias por despido ineficaz.

- la Función Judicial, Departamento de Jurimetría, para que faciliten una estadística de demandas laborales que se hayan presentado en la ciudad de Machala que conciernan a despido ineficaz (mujer embarazada, mujer en período de lactancia, dirigentes sindicales o cualquier otra circunstancia que permita este tipo de vulneración de derecho al trabajo).

Las fuentes secundarias de información a utilizarse serán: libros, periódicos, actas notariales y documentos digitales en especial artículos científicos.

Como método de investigación se utilizará el analítico y el inductivo. El método analítico puesto que es la requerida en el estudio de casos y leyes que rigen esta norma y el método inductivo puesto que se analizarán una cantidad relevante de casos particulares para establecer en general las vulnerabilidades existentes en la normativa legal sobre el tema.

\section{Métodos de interpretación del Derecho que se va a utilizar.}

El Derecho dispone de varios métodos de interpretación. Se utilizarán 2 de ellos: interpretación acorde al uso interpretativo del derecho y la interpretación analógica extensiva.

\section{Interpretación acorde al uso interpretativo del derecho}

En toda investigación, se requiere realizar un análisis de las disposiciones legales, puesto que de acuerdo a éstas se determinan los comportamientos humanos en general. En especial cuando se trata de personas que están siendo involucradas en procedimientos judiciales, debe recordarse que las normas son creadas contemplando siempre una posición justa e imparcial.

Para este caso se tratará el despido ineficaz desde la óptica constitucional, es decir garantizando al empleado la estabilidad laboral, si fuese lo justo. 


\section{Interpretación analógica o extensiva}

Se debe observar cierta similitud entre lo descrito teóricamente y lo que se implementa en el ámbito profesional. En nuestro caso en particular, se contemplará que las leyes vigentes se cumplan.

\section{RESULTADOS, ANÁLISIS Y DISCUSIÓN}

En Ecuador, específicamente en la ciudad de Machala, provincia de El Oro, la Función Judicial está representada por el Consejo de la Judicatura en donde se reciben, gestionan y reposan todas las demandas presentadas.

\subsection{Análisis descriptivo - Estadística sobre el despido ineficaz}

El departamento de Jurimetría de dicho Consejo legal facilitó copias de varios documentos in situ para realizar un análisis descriptivo y documental. Al igual que de la Inspectoría de Trabajo de la provincia de El Oro al que se acudió a solicitar evidencias de denuncias por despido ineficaz.

Con estos datos, se realiza un análisis descriptivo y se presenta una estadística de lo encontrado.

Las demandas laborales en Ecuador generalmente son por: despido intempestivo, desahucio, despido ineficaz, por acoso laboral y sexual, por modificación sustancial de condiciones de trabajo, sobre daños en accidente de trabajo, por incapacidad permanente, entre otras. A continuación, se ilustra la cantidad de demandas laborales que han sido gestionadas por la Unidad Judicial Laboral del Consejo de la Judicatura en la ciudad de Machala desde el año 2017 al 2020 en la tabla 1

Tabla 1: Demandas laborales que ha gestionado el Consejo de la Judicatura de la provincia de El Oro

\begin{tabular}{lcccc}
\hline \multicolumn{1}{c}{ Demandas laborales } & $\mathbf{2 0 1 7}$ & $\mathbf{2 0 1 8}$ & $\mathbf{2 0 1 9}$ & $\mathbf{2 0 2 0}$ \\
\hline Despido intempestivo & 300 & 400 & 420 & 450 \\
\hline Desahucio & 200 & 280 & 180 & 300 \\
\hline Despido ineficaz & $\mathbf{3}$ & 10 & $\mathbf{1 3}$ & $\mathbf{1 5}$ \\
\hline Por acoso laboral y/o sexual & 0 & 0 & 0 & 3 \\
\hline $\begin{array}{l}\text { Por modificación sustancial de condiciones } \\
\text { de trabajo }\end{array}$ & 250 & 180 & 100 & 80 \\
\hline $\begin{array}{l}\text { Por jubilación patronal } \\
\text { Sobre daños de accidente de trabajo }\end{array}$ & 50 & 30 & 20 & 12 \\
\hline Por incapacidad permanente & 5 & 10 & 7 & 4 \\
\hline Otros tipos de demandas laborales & 80 & 70 & 60 & 70 \\
\hline
\end{tabular}

Fuente: Consejo de la Judicatura de la provincia de El Oro, Ecuador Elaborado por: Martínez (2020) 
El número de demandas sobre despido ineficaz que se han presentado en los últimos 4 años han sido: 2017: 3 demandas; 2018, 10 demandas; 2019: 13 demandas y 2020: 15 demandas.

\section{Lo descrito se ilustra en la figura 2.}

Figura 2. Demandas por despido ineficaz gestionadas en Machala, Ecuador.

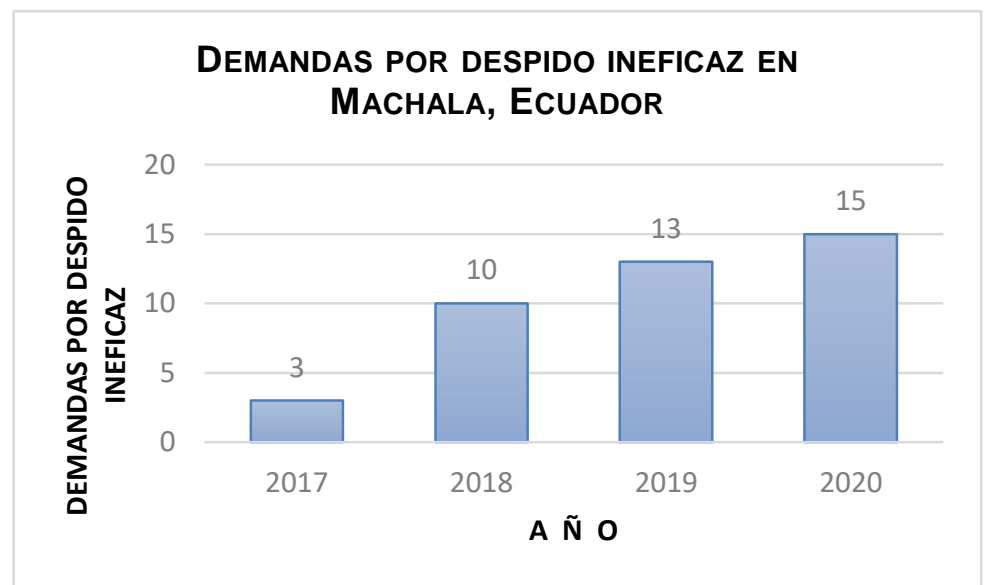

Fuente. Consejo de la Judicatura de la provincia de El Oro, Ecuador.

De la tabla anterior, se tiene que, entre los casos presentados de demandas por despido ineficaz, la Función Judicial indicó que en el año 2020, aproximadamente un 87\% de los casos son de mujeres embarazadas, mujeres en períodos de lactancia y dirigentes sindicales. Es decir, en la mayoría de las demandas de despido ineficaz predominan como protagonistas personas de sexo femenino. Se lo ilustra en la figura 3.

Figura 3. Casos de despido ineficaz en Machala, Ecuador

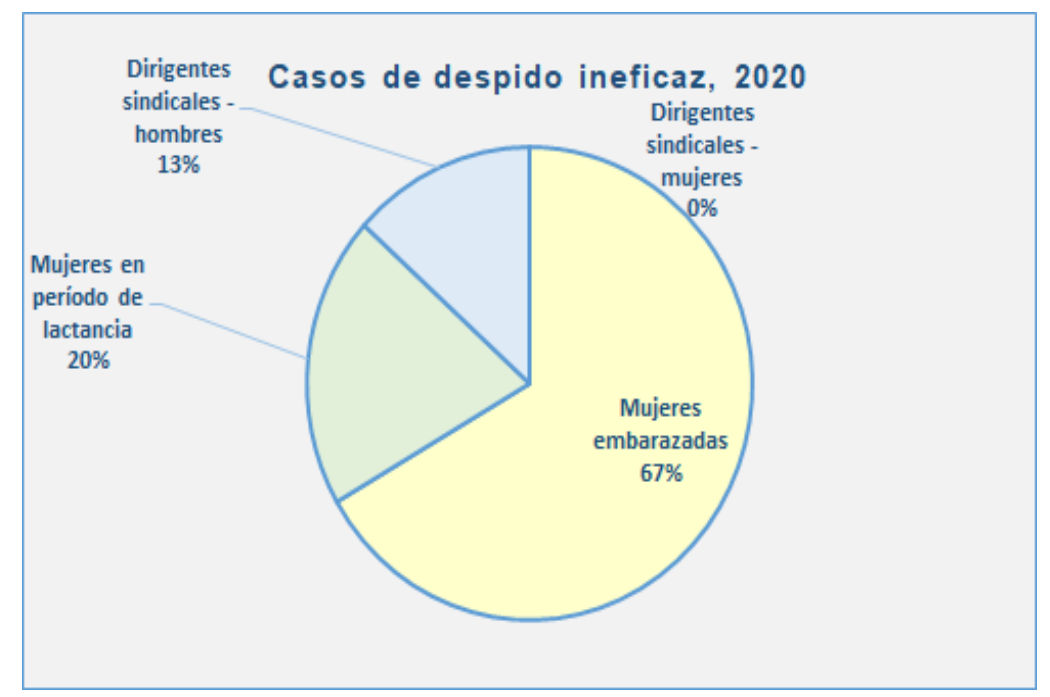

Fuente. Consejo de la Judicatura de la provincia de El Oro, Ecuador. 
En la Función Judicial también acotaron que, del número de demandas laborales por este tipo de despido, en promedio, llegan a juicio aproximadamente 10 demandas en los últimos 4 años; lo cual se presenta en la figura 4.

Figura 4. Demandas laborales por despido ineficaz que llegan a juicio.

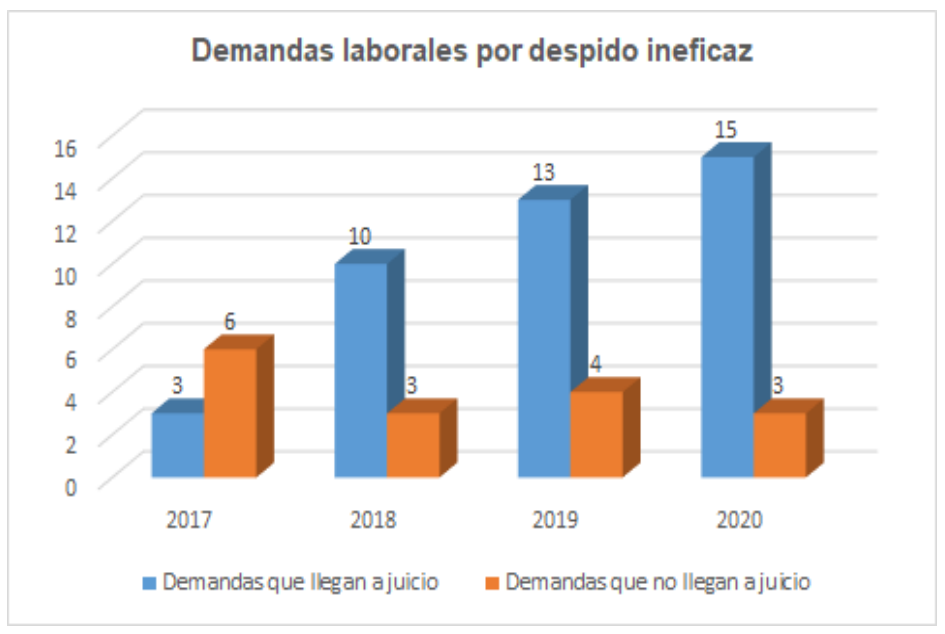

Fuente. Consejo de la Judicatura de la provincia de El Oro, Ecuador.

En cuanto al género de los empleados que han sido parte de demandas laborales por despido ineficaz se encontró que en los últimos 4 años (2017 al 2020) no han existido casos con mujeres como dirigentes sindicales; la mayoría de los casos han sido teniendo como parte del proceso a mujeres embarazadas; destacan también las mujeres en período de lactancia y en menor cantidad hombres en calidad de dirigentes sindicales. Lo expuesto se muestra en la Tabla 2.

Tabla 2: Género de los empleados que han sido parte del despido ineficaz.

\begin{tabular}{lccccc}
\hline \multicolumn{1}{c}{$\begin{array}{c}\text { Demandas laborales por } \\
\text { despido ineficaz }\end{array}$} & $\mathbf{2 0 1 7}$ & $\mathbf{2 0 1 8}$ & $\mathbf{2 0 1 9}$ & $\mathbf{2 0 2 0}$ \\
\hline Mujeres embarazadas & 1 & 5 & 8 & 10 \\
\hline Mujeres en período de lactancia & 1 & 3 & 4 & 3 \\
\hline Dirigentes sindicales - hombres & 1 & 2 & 1 & 2 \\
\hline Dirigentes sindicales - mujeres & 0 & 0 & 0 & 0 \\
\hline Total & 3 & 10 & 13 & 15 \\
\hline
\end{tabular}

Fuente: Consejo de la Judicatura de la provincia de El Oro, Ecuador Elaborado por: Martínez (2020)

\subsection{Discusión}

Luego de realizar un análisis documental de: 
a) La Constitución de la República del Ecuador, el Código de Trabajo y el Código Orgánico General de Procesos y Ley de Justicia Laboral.

b) las evidencias de denuncias (fotos, referencias personales, pruebas de embarazo, memorándum, emails, documentos, etc) sobre despido ineficaz provistas in situ por la Inspectoría de trabajo y

c) las demandas - juicios sobre despido ineficaz facilitadas in situ por el Consejo de la Judicatura de Machala, provincia del El Oro y

En vista de los casos que se presentan anualmente sobre despido ineficaz, donde en su mayoría una de las partes son mujeres embarazadas o en período de lactancia; se precisa que debido a que no se ha contemplado legalmente un reglamento o instructivo elaborado por el Ministerio de Trabajo con el cual que se asegure que:

a) el empleador conozca que se le ha notificado del embarazo de la trabajadora antes del juicio para que la misma antes de un proceso judicial notifique de su embarazo en su lugar de trabajo.

b) Y con respecto a dirigentes sindicales, se establezca una tabla de indemnización de acuerdo al cargo que ocupa.

Por otra parte, del mismo análisis documental y en base a la experiencia de los autores se citan a continuación las siguientes vulnerabilidades existentes en la ley sobre despido ineficaz:

a) No se sabe con certeza si el empleador conoce si la trabajadora está embarazada, y aun así en ocasiones le debe pagar indemnizaciones.

b) No se sabe expresamente que la trabajadora haya dado a conocer su estado de embarazo.

c) La Inspectoría de trabajo no notifica al empleador del estado de gravidez de la trabajadora de manera oportuna.

d) No existe la mediación obligatoria en la Inspectoría de trabajo, para solucionar problemas con la trabajadora embarazada y disponer sea reintegrada de inmediato a su trabajo.

e) La trabajadora embarazada busca más una indemnización que el reintegro a su trabajo, de esta forma no se cumple con el espíritu de esta disposición, el cual es precautelar el empleo. 
f) Debe existir obligatoriedad de dar a conocer por parte de la trabajadora por los medios de comunicación existentes dentro de un plazo determinado que se encuentra embarazada.

g) Debería ser obligatorio que la trabajadora se reintegre a su lugar de trabajo en caso de haber sido despedida injustificadamente, y que se pague indemnización de despido ineficaz si no es reintegrada a su trabajo.

\section{CONCLUSIONES}

La cantidad de evidencias de denuncias y demandas sobre despido ineficaz que se presentan en la Inspectoría de Trabajo y en la Corte Provincial de Justicia de El Oro, muchas de estas denuncias llegan a juicio y al haber existido inconformidad en ciertas ocasiones de alguna de las partes, permiten precisar que existieron vulnerabilidades en este tipo de despido, al menos en los últimos 4 años.

En los años analizados y en la actualidad, el despido ineficaz siendo un trámite expedito, el(la) trabajador(a) debe presentar su demanda en el plazo máximo de 30 días una vez perpetrado el despido; esto ofrece ventajas y desventajas para el(la) trabajador(a) por cuanto podría ser un corto tiempo para reunir las pruebas del caso.

La Inspectoría de Trabajo debió prestar y debería prestar la oportuna colaboración respecto a las notificaciones de este tipo de despidos a sus empleadores, para que quede constancia que el empleador tiene total conocimiento del mismo.

Deberían haberse realizado talleres de capacitación e información a los trabajadores que se encuentren en los casos narrados por el despido en estudio.

\section{RECOMENDACIONES}

El Ministerio de Trabajo debe contemplar la posibilidad de elaborar un instructivo para que en los casos de despido ineficaz se pueda tratar con mayor objetividad a las partes involucradas.

Se sugiere que las empresas con cierta periodicidad soliciten que las empleadas se realicen exámenes de embarazo para poder certificar si se encuentran en un estado de gravidez.

Se recomienda también, que para el caso de los dirigentes sindicales el Ministerio de Trabajo notifique a sus empleadores cuando tenga conocimiento de que estos han sido despedidos.

Debe ser obligatorio que la trabajadora en estos casos de despido ineficaz se reintegre a su lugar de trabajo por un período de tiempo para garantizar la estabilidad laboral o en su 
defecto pueda denunciar que se están cometiendo arbitrariedades en el caso de su empleador.

\section{REFERENCIAS BIBLIOGRÁFICAS}

Argudo, L., González, M., \& Tamayo, F. (2020). La garantía de inamovilidad y el despido ineficaz en la República del Ecuador. Polo del conocimiento, 429-447. Obtenido de https://dialnet.unirioja.es/servlet/articulo?codigo=7435334

Arias, J. (2018). Análisis jurídico sobre el despido ineficaz de las mujeres embarazadas en el período de prueba. Ibarra, Ecuador.

Arteaga, A. (2018). El despido ineficaz y su relación con el principio de no discriminación a la estabilidad. San Gregorio, 38-45. Obtenido de https://dialnet.unirioja.es/servlet/articulo?codigo $=6841001$

Asamblea Nacional. (2015). Código orgánico general de procesos. Ecuador.

Asamblea Nacional. (2017). Código del trabajo. Ecuador.

Asamblea Nacional. (2018). Constitución de la República del Ecuador. Ecuador.

Balbín, N. (2018). El despido injustificado como instituto de control social. REDEA.

Derechos acción, 79-95. Obtenido de https://www.google.com/url? sa=t\&rct=j\&q=\&esrc=s\&source=web\&cd=\&cad=r ja\&uact=8\&ved=2ahUKEwjv6tnjme_sAhWNwVkKHRplAgM4HhAWMAd6B AgCEAI\&url=https\%3A\%2F\%2Frevistas.unlp.edu.ar\%2FReDeA\%2Farticle\%2 Fdownload\%2F5667\%2F4682\%2F\&usg=AOvVaw1EDrWyp6Vw2aMF4763t4 Gp

Bernal, C. (2010). Metodología de la investigación. Bogotá: Pearson.

Blancas Bustamante, C. (2005). La protección contra el despido lesivo de los derechos fundamentales en la jurisdicción constitucional. Derecho y Sociedad, 154-171. Obtenido https://www.google.com/url?sa=t\&rct=j\&q=\&esrc=s\&source=web\&cd=\&cad=r ja\&uact=8\&ved=2ahUKEwjv6tnjme_sAhWNwVkKHRplAgM4HhAWMAV6B AgGEAI\&url=http\%3A\%2F\%2Frevistas.pucp.edu.pe\%2Findex.php\%2Fderech oysociedad\%2Farticle\%2Fdownload\%2F17366\%2F17651\%2F0\&usg=AOvVa w21XZ

El despido intempestivo en la ciudad de Machala. Aplicación del Código de Trabajo. (2019). Universidad y Sociedad, 43-52. Obtenido de 
http://scielo.sld.cu/scielo.php?script=sci_arttext\&pid=S2218-

36202019000400043

Enciclopedia jurídica. (2020). Obtenido de http://www.enciclopedia-juridica.com/

Galindo, K., \& Fuentes, V. (2018). Inexistencia de término para contestar la acción del despido ineficaz. Observatorio de la Economía Latinoamericana. Obtenido de https://www.eumed.net/rev/oel/2018/07/despido-ineficaz.html

Goyes, O. (2019). La estabilidad laboral y el despido ineficaz de las personas con discapacidad. Ambato, Ecuador.

Hernández Sampieri, R., Fernández Collado, C., \& Baptista Lucio, P. (2010). Metodología de la investigación. México: McGraw Hill.

Jácome, J. (2019). Despido ineficaz y la protección del derecho al trabajo a grupos de atención prioritaria. Debate jurídico Ecuador, 150-158. Obtenido de 45.238.216.13 > index.php > DJE > article > download

Jaramillo, J., \& Puertas, L. (2017). El despido ineficaz en la legislación ecuatoriana. Un análisis de las reformas incorporadas en el Código de Trabajo para las madres trabajadoras. Revista internacional y comparada de Relaciones laborales y derecho del $27 . \quad$ Obtenido de http://ejcls.adapt.it/index.php/rlde_adapt/article/view/530

Marriot, G., \& Correa, S. (2018). Caducidad de la acción de despido ineficaz en la mujer embarazada. Observatorio de la Economía Latinoamericana. Obtenido de https://www.eumed.net/rev/oel/2018/02/despido-ineficaz-embarazadas.html

Ochoa Ochoa, M., \& Morales Guevara, G. (2020). La mujer embarazada y sus derechos laborales en Ecuador. Dilemas Contemporáneos: Educación, Política y Valores. Obtenido

de https://www.dilemascontemporaneoseducacionpoliticayvalores.com/index.php/d ilemas

Pacheco Ramos, J., \& Muñoz Sangoquiza, M. (2020). Reforma al artículo 195.1 del Código del Trabajo; para que se amplíe la protección del Despido Ineficaz al sector de los trabajadores que tienen discapacidad. Dominio de las Ciencias, 347365. doi:http://dx.doi.org/10.23857/dc.v6i2.1172

Pensabene Lionti, G. (2015). El artículo 18 del Estatuto de los trabajadores italianos a la luz de las últimas reformas laborales. Actualidad Jurídica Iberoamericana, 641- 
654. Obtenido de http://idibe.org/wp-content/uploads/2013/09/33.-GiuseppinaPensabene.pdf

Quevedo, A., \& Tigua, A. (3 de marzo de 2017). Desafíos del despido ineficaz en el Ecuador. Guayaquil, Ecuador.

Sarango Alcívar, J., \& Vivanco Vargas, G. (2018). El despido intempestivo frente a los derechos constitucionales ecuatorianos. Universidad y Sociedad, 181-186. Obtenido de http://rus.ucf.edu.cu/index.php/rus

Secretaría Nacional de Planificación y Desarrollo. (2017). Plan Nacional para el Buen Vivir 2017 - 2021. Quito, Ecuador. 